Research Paper

\title{
Quality of life in patients with multiple sclerosis: A study with patients and caregivers
}

\author{
Martim Santos, Cláudia Sousa, Marta Pereira, M. Graça Pereira* \\ Department of Applied Psychology, School of Psychology, University of Minho, Braga, Portugal
}

\section{A R T I C L E I N F O}

\section{Article history:}

Received 18 September 2018

Received in revised form

23 February 2019

Accepted 18 March 2019

Data was presented at the $12^{\circ} 12$ th Health Psychology National Conference- Portugal.

\section{Keywords:}

Multiple sclerosis

Patients

Caregivers

Quality of life

\begin{abstract}
A B S T R A C T
Background: Multiple Sclerosis (MS) is a chronic disease that affects patients' quality of life and requires long term demanding care.

Objective: The purpose of this study was to examine the relationships between patients and caregivers' variables regarding patients' quality of life, the moderating role of marital satisfaction between patients' psychological morbidity and quality of life, and the contribution of patient and caregiver variables towards patients' quality of life.

Methods: The sample included 100 patients with MS and 72 caregivers. Participants' variables were assessed using self-report measures. The design of this quantitative study was transversal.

Results: Marital satisfaction moderated the relationship between patients' anxiety and mental quality of life. Patients' perception of illness identity and consequences together with caregivers' depressive symptoms were mediators between patients' depression and quality of life. Burden also played a mediator role in the relationship between patients' depressive symptoms, disability level, and physical quality of life.

Conclusion: Therefore, intervention in multiple sclerosis should be delivered in a dyadic context.
\end{abstract}

() 2019 Elsevier Inc. All rights reserved.
Multiple sclerosis (MS) refers to a chronic, autoimmune and demyelinating inflammatory pathology that affects the Central Nervous System (CNS) in multiple areas, namely the cerebral peduncle and periventricular areas of the brain, optic nerves, and spinal cord. ${ }^{1-3}$ MS is characterized by a diverse set of symptoms and lesions, which can cause serious physical alterations, compromise cognitive functioning, and even trigger neurological problems. ${ }^{1}$

MS etiology is not yet fully understood. However, it is considered a multifactorial disease with environmental and genetic variables being risk factors with immunological implications that alter myelin (white matter)., ${ }^{4,5}$ Myelin, when degraded due to the inflammatory process inherent to the disease (flare-up), can lead to scarring (plaques/lesions) which, in turn, leads to a CNS impairment in the transmission of impulses, resulting in complications in the functioning of several organs. ${ }^{6}$

In Portugal, there are approximately 5,000 individuals with $\mathrm{MS}{ }^{7}$ and globally more than 2.3 million. ${ }^{8} \mathrm{MS}$ is more frequent in women,

\footnotetext{
* Corresponding author. Department of Applied Psychology, School of Psychology, University of Minho, Campus de Gualtar, 4710-057 Braga, Portugal.

E-mail address: gracep@psi.uminho.pt (M.G. Pereira).
}

who are on average affected two to three times more than men. ${ }^{8,9}$ It is not possible to predict the development of MS since the severity or progression is variable. ${ }^{10}$ However, flare-ups, as a result of symptoms or episodes of exacerbated symptomatology, are a central feature of the disease and tend to progress leading the patient to a state of high disability. ${ }^{11}$ According to Lublin et al., ${ }^{11}$ MS can be classified by evolution and type, namely Relapsing-Remitting MS (RRMS), Primary Progressive MS (PPMS), and Secondary Progressive MS (SPMS) and Progressive Relapsing (PRMS). Usually, the first symptoms of MS begin to appear in young adults. ${ }^{3,12}$ The main reported complaints are predominantly sensory (40\%) and motor (39\%), namely double vision, motor weakness, intestinal and genitourinary problems, fatigue, tremors, speech and pain disorders, ${ }^{8,13}$ which affect patients' quality of life $(\mathrm{QoL}) .{ }^{14}$

Depression and anxiety are among the most common psychological symptoms in MS patients and, compared to the general population, are described as severe. ${ }^{15}$ The prevalence of psychological morbidity in this population has been increasing, ranging from $14 \%$ to $54 \%{ }^{16}$ According to the systematic review by Marrie et al., ${ }^{17}$ psychological morbidity affects approximately $20 \%$ of MS patients. In a recent meta-analysis with more than 87,000 European and North American patients, there were high prevalence 
rates of depression (31\%) and anxiety (22\%). ${ }^{18}$ Depression is one of the most significant negative predictors of patients' QoL. ${ }^{19}$ Additionally, several studies with MS patients indicate that women are significantly more anxious, ${ }^{20}$ that high levels of anxiety are associated with higher incapacity levels ${ }^{21}$ and low education is related to high levels of anxiety. ${ }^{22,23}$ Also, changes in professional status after diagnosis and high anxiety ${ }^{24,25}$ have also been reported as well as associations between anxiety and family problems. ${ }^{26}$ Janssens et al. ${ }^{14}$ also showed that in addition to patients, caregivers also experience a marked increase in anxiety in the first few years after diagnosis. Another study revealed that caregivers also presentdepressive symptoms, especially if they are younger. ${ }^{27}$

The need for readjustment to the demands of the disease negatively affects the patients and their caregivers with implications in QoL, (e.g., daily work) ${ }^{28,29}$ and repercussions on psychological morbidity and physical symptoms. ${ }^{29,30}$ Caregivers of MS patients, reported feeling overwhelmed and the degree of patients' disability have been positively associated with caregiver burden. ${ }^{31}$ Thus, caregiving in MS deserve increasing recognition, since it plays a key role in the evolution of the disease, especially in patients with high disability. ${ }^{32}$

There is a gap in the literature regarding the assessment of marital satisfaction in MS patients and their caregivers, considering that most caregivers are patients' spouses. ${ }^{33}$ Marital satisfaction is positively associated with QoL. ${ }^{34}$ Gordon and Perrone ${ }^{35}$ found that in cases of chronic illness, intimacy is negatively affected, since one partenr feels responsible for providing daily care to another, with an impact on their marital satisfaction. According to Pruchno, Wilson-Genderson, and Cartwright, ${ }^{36}$ chronic patients, on average, report greater marital satisfaction compared to their partners and there is a gradual decline in marital satisfaction in caregivers and, as the disease progresses, a negative association between depressive symptoms and marital satisfaction has also been found. Therefore, it would be important to evaluate the moderating role of marital satisfaction in the relationship between psychological morbidity and QoL to clarify these aspects, since the literature is scarce.

Patients' representations are determinant for adaptation to MS, influencing their QoL. ${ }^{37}$ The unpredictability of the disease and changes in social roles and functioning seem to influence illness representations in patients. ${ }^{38}$ According to French, Cooper, and Weinman $^{39}$ the individual perceptions that chronic patients have regarding their symptomatology and medical condition has implications on QoL. Aalto, Aro, Weinman et al. ${ }^{40}$ argue that a stronger identity with the illness and a greater perception of the associated consequences was associated with poorer QoL. In fact, patients who perceive a greater impact of the MS as well as a greater severity of symptoms, and a chronic duration of the disease, report worse QoL. ${ }^{41,42}$

The impact of MS on patients' QoL is undeniable. However, there are other variables whose influence are significant, such as duration of diagnosis that is associated with worse physical and mental QoL, ${ }^{43,44}$ the degree of disability, and the evolution of the disease, which also appear to be negatively associated with QoL. ${ }^{45}$

This study was conceptually based on the Psychosocial Adaptation Model for Chronic Disease. ${ }^{46}$ This theoretical model was chosen since the main outcome is quality of life and the model considers, in the process of illness adaptation, the influence of contextual variables such as socio-demographic (e.g. gender, age, marital status, professional status, and education), medical/clinical (e.g. duration of illness, degree of incapacity, illness classification, type of therapy); psychological variables such as psychological attributes (e.g. marital satisfaction and illness representations), as well as emotional reactions to the illness (e.g. psychological morbidity). The model also includes moderation and mediation relationships between the variables and QoL (e.g. marital satisfaction moderates the relationship between patients' emotional reaction to the illness and QoL; patients' illness representations mediates the relationship between emotional reaction to the illness and QoL and between patients' sociodemographic variables and QoL; caregiver burden mediates the relationship between patients' emotional reaction to the illness and patients' sociodemographic variables and QoL. Therefore, having the model as a basis, the following hypothesis were formulated: 1) marital satisfaction plays a moderator role in the relationship between patients' psychological morbidity (emotional reaction to the illness) and QoL and 2) caregiver burden plays a mediation role in the relationship between patients' depressive symptomatology and physical QoL; patients' perception of the illness identity and caregivers' depressive symptomatology play a mediation role in the relationship between patients' depressive symptomatology and mental QoL; patients' depressive symptomatology plays a mediation role in the relationship between patients' age and physical QoL, and also between patients' age and mental QoL. Finally, caregiver burden plays a mediation role in the relationship between the patients' level of disability and physical QoL.

\section{Methods}

\section{Participants}

Data were collected in a major hospital in the North of Portugal and the sample comprised 172 participants (100 patients diagnosed with MS and 72 caregivers). Some patients did not have caregivers, so the number of caregivers was lower than the patients. The study used a transversal design. The criteria for patient inclusion were: 1) to be enrolled in the Neurology/Psychiatry Consultation at the Hospital; 2) age 16 or older; 3) diagnosis of MS. For caregivers: being the person that accompanied the patient, the day of the consultation. Assessment took place the same day of the neurology consultation.

\section{Instruments}

Sociodemographic and Clinical Questionnaire that assesses sociodemographic variables (e.g., age, sex) and clinical variables (e.g., duration of diagnosis, therapy) and evaluates the patient's relationship with the caregiver and the perception of the impact of the illness on the family dynamics. It also included the Kurtzke Expanded Disability Status Scale (EDSS) ${ }^{47}$ to assess the patients' disability level.

Multiple Sclerosis Quality of Life ${ }^{48}$ (MSQOL-54; Portuguese version by Pedro and Pais-Ribeiro ${ }^{49}$ ). It evaluates $\mathrm{QoL}$ in patients with MS. This scale includes items from the 36-Item Short-Form Health Survey (SF-36) with 18 additional items, making up 54 items. It presents 12 dimensions that can be divided into two major domains (Mental QoL and Physical QoL). Mental QoL encompasses the dimensions of emotional well-being, role limitations due to emotional problems, overall quality of life, and cognitive function. Physical QoL includes the dimensions of pain, role limitations due to physical problems, physical health, sexual function, social function, energy, health perceptions, and health distress. Higher scores indicate better QoL. In the original version, Cronbach's alphas for each dimension range from 0.75 to 0.96 . And the alpha for Mental and Physical QoL was 0.81 and 0.88 , respectively. In this study only those two dimensions were used with an alpha of. 91 for Mental QoL and 0.73 for Physical QoL.

Illness Perception Questionnaire-Revised ${ }^{41}$ (IPQ-R; Portuguese version of Figueiras, Machado, and Alves ${ }^{50}$ ) evaluates patients' cognitive and emotional representations of the illness. It has 38 items divided into nine subscales (Identity, Acute/Chronic 
Timeline, Consequences, Personal Control, Treatment Control, Illness Coherence, Cyclical Timeline, Emotional Representations and Causes). Higher scores on the subscales Acute/chronic timeline and Cyclical timeline indicate a more chronic perception of the illness and a perception of greater periodicity, respectively. Higher scores in the Personal Control and Treatment Control subscales indicate a greater perception of control into both subscales. In the Emotional representations' subscale, the higher the score the more negative, the representation. Higher scores in the Consequences and Illness Coherence subscales, indicate a more negative perception and a poor understanding of the illness, respectively. In the original version, Cronbach's alphas ranged between 0.73 and 0.82 and in the Portuguese version, between 0.55 and 0.83 . In this study, the Cronbach alphas for the respective subscales were: 0.71 (Identity), 0.82 (Acute/Chronic timeline), 0.73 (Consequences), 0.51 (Personal control), 0.54 (Treatment control), 0.79 (Illness coherence), 0.71 (Cyclical timeline) and 0.85 (Emotional representations).

Hospital Anxiety and Depression Scale ${ }^{51}$ (HADS; Portuguese version by Pais-Ribeiro, Silva, Ferreira et al. $^{52}$ ). This questionnaire assesses depression and anxiety in patients and contains 14 items, seven for each of the two subscales: depression and anxiety scored in a four-point Likert scale. Higher scores indicate greater psychological morbidity. In the original version, Cronbach's alphas were .76 for anxiety and 0.72 for depression. Sousa and Pereira ${ }^{53}$ validated the scale in MS patients and found alphas of .81 for the anxiety subscale, 0.78 for the depression subscale and 0.87 for the full scale. In the present study the alphas were $.87, .78$ and 0.81 for the full scale, depression and anxiety subscales, respectively.

Index of Marital Satisfaction ${ }^{54}$ (IMS; Portuguese version of Pereira, Ramalho, and Dias ${ }^{55}$ ). This instrument is used to evaluate problems in marital relationships, and contains 25 items that assess the degree, magnitude, or severity of marital problems using a seven-point Likert-type scale, ranging from "none of the time" (1) to "all of the time" (7) (e.g. "I feel that I would not choose the same partner if I had it over again", "I feel that our relationship is breaking up" and "My partner is a real comfort to me"). Low scores indicate higher marital satisfaction. In the original version, the total Cronbach's alpha is .96 and in the present study .94.

Caregiver Reaction Assessment ${ }^{56}$ (CRA; Portuguese version by Pereira et al $^{57}$ ). This scale evaluates the responses/reactions of the caregivers caring for a patient with a physical pathology and allows a global evaluation of the burden. It contains 24 items, divided by five subscales: lack of family support, caregiver's esteem, impact on finances, impact on schedule, and impact on health. Scoring uses a five-point Likert-type scale where 1 equals "strongly disagree" and 5 "strongly agree." High scores indicate more burden. In the original version Cronbach alphas for each subscale are: 0.90 (caregiver's esteem), 0.85 (lack of family support), 0.81 (impact on finances), 0.82 (impact on schedule), and 0.80 (impact on health). In the Portuguese version alphas were $0.95,0.80,0.57,0.82$ and 0.64 , for each subscale, respectively, and in the present study, alphas were $.67,0.83,0.80,0.76$ and.72, respectively.

State Trait Anxiety Inventory ${ }^{58}$ (STAI; Portuguese version of Silva ${ }^{59}$ ). Used to assess anxiety in caregivers, this scale is composed of two subscales, Trait Anxiety (Anx-T) and State Anxiety (Anx-S), each consisting of 20 items. Scoring uses a four-point Likert-type scale where 0 corresponds to "almost never" and 3 to "almost always". Cronbach's alpha for the Anxiety-T subscale is 0.86 and 0.85 for Anxiety-S, whereas in the Portuguese version they were 0.90 and 0.80 , respectively and in this study, .89 and .91 , respectively.

Beck Depression Inventory ${ }^{60}$ (BDI; Portuguese version by McIntyre and Araújo-Soares ${ }^{61}$ ). This questionnaire assesses depression in caregivers, it consists of 21 items scored in a fourpoint Likert-type scale where 0 is "low" and 3 "high". High results indicate more depression. In the Portuguese version the total alpha was 0.86 and in the original version, 0.81 , as in the prsent study.

\section{Procedure}

This study was approved by the Ethics Committee of a major hospital in Northen Portugal. The selection of patients and caregivers was performed based on the inclusion criteria and with the neurologists' assistance. The day of the consultation, the patient and caregiver were informed about the objectives of the study and invited to participate by the attending physician. Patients and caregivers signed an informed consent regarding their participation in the study.

\section{Data analysis}

The path analysis was performed with IBM $^{\circledR}$ SPSS $^{\circledR}$ Amos ${ }^{\mathrm{TM}} 24$ (IBM, Armonk, NY). To test the multivariate regression model (path analysis) patient variables correlated with QoL were included: duration of diagnosis, age, degree of disability, psychological morbidity, illness identity, emotional representations, illness consequences, and marital satisfaction and caregiver variables: burden and anxious and depressive symptoms. Taking in consideration the number of variables, the sample size was considered adequate. ${ }^{62,63}$ Moderation was analyzed with the macro process ${ }^{64}{\text { using } \text { IBM }^{\circledR}}^{\circledR}$ SPSS $^{\circledR}$ software (Statistical Package for the Social Sciences; IBM, Armonk, NY), version 24.0.

\section{Results}

\section{Sample characteristics}

Of the patients' sample, 75 ( ) were female. The mean age was 39.43 years old $(S D=10.52)$, ranging from 16 to 65 years old. Regarding marital status, $64 \%$ of the patients were married and $69 \%$ had children. Regarding education, $78 \%$ had primary education or higher. Before the diagnosis, 76\% were professionally active, with only $53 \%$ remaining active. The majority of patients (83\%) had RRMS and 13\% SPMM. Regarding the duration of the disease, $42 \%$ had been diagnosed with MS for less than three years and $91 \%$ received specific and symptomatic therapy. Finally, the majority of patients (89\%) had a lower degree of disability (less than four).

Regarding caregivers, 29 (40\%) were women, with a mean age of $42.43(S D=11.98)$, ranging from 18 to 65 years old, and with a variable relationship with the patient, that is, $77 \%$ were spouses, $15.27 \%$ parents, and $5.5 \%$ children. In terms of education, most participants had primary education or above (77\%) and, $75 \%$ were professionally active. Concerning the influence of MS in the family, $52 \%$ of caregivers reported that MS significantly influenced their family life.

\section{Relationship between patient and caregiver's variables with patients' QoL}

In patients, there was a negative association between Physical QoL and depression $(\mathrm{r}=-.526, \mathrm{p}<.01)$, illness consequences $(\mathrm{r}=-0.462, \quad \mathrm{p}<.01)$, emotional representations $(\mathrm{r}=-0.299$, $\mathrm{p}<.01)$ and identity $(\mathrm{r}=-0.215, \mathrm{p}<.05)$. A positive association was found between Physical QoL and control of treatment $(r=-0.218$, $\mathrm{p}<.05$ ) and a negative association between Mental QoL and marital satisfaction $(\mathrm{r}=-0.292, \mathrm{p}<.05)$, anxiety $(\mathrm{r}=-669, \mathrm{p}<.01)$, depression $(\mathrm{r}=-745, \mathrm{p}<.01)$, illness consequences $(\mathrm{r}=-0.488$, $\mathrm{p}<.01)$, illness coherence $(\mathrm{r}=-518, \mathrm{p}<.01)$, cyclic duration, $\mathrm{p}<.01)$, emotional representations $(\mathrm{r}=-545, \mathrm{p}<.01)$ and identity $(\mathrm{r}=-465, \mathrm{p}<.01)$. 
In caregivers, the results revealed a significant negative association between burden and patient's Physical QoL $(r=-0.503$, $\mathrm{p}<.01)$ and Mental QoL $(\mathrm{r}=-326, \mathrm{p}<.01)$ and between depression and patients' Physical QoL $(\mathrm{r}=-369, \mathrm{p}<.01)$ and Mental QoL $(\mathrm{r}=-0.289, \mathrm{p}<.05)$ (Table 1$)$.

There was also a negative association between patient's physical QoL and degree of disability $(\mathrm{r}=-512, \mathrm{p}<.01)$ and age. There were no significant associations between sex, marital status, education, and QoL. In caregivers, no significant associations were found between sex, age, education and patients' QoL.

Marital satisfaction as a moderator in the relationship between patients' psychological morbidity and QoL

The model that tested the moderating role of marital satisfaction in the relationship between patients' anxious symptomatology and mental QoL was significant $(\mathrm{F}(3,65)=32.9136, p<.0001$, $\beta=-01,95 \%$ CI. 0177, -0.0020$], t=-2.52, p<.05)$, explaining $73.1 \%$ of the variance. When marital satisfaction was low, there was a negative relationship between anxious symptomatology and mental QoL ( $\beta=-.20,95 \%$ CI [-0.3007, -0.0987$], t=-3.95, p<.01$ ). When marital satisfaction was high, there was also a negative relationship $(\beta=-0.44,95 \%$ CI $[-5766,-0.2989], t=-6.30$, $p<.0001$ ), more intense in the latter situation, i.e. the relationship was stronger in patients more satisfied with their marital relationship. Marital satisfaction did not moderate the relationship between depressive symptomatology and mental QoL ( $\beta=-.0041$, $95 \% \mathrm{CI}[-0.0098,0.0016], t=-1.41, p>.05$ ), (Fig. 1 ). The moderating role of marital satisfaction in the relationship between depressive symptomatology and physical QoL, and between anxious symptomatology and physical QoL was not tested since the required statistic assumptions were not present (Field, 2009).

\section{Contributors to patients' QoL}

The results of the path analysis showed that the adjustment statistics indicated a good fit $(\chi 2=22.95(18)=1.28, p>.05$, $\mathrm{GFI}=0.95, \mathrm{AGFI}=0.88, \mathrm{CFI}=0.98, \mathrm{TLI}=0.97$, $\mathrm{RMSEA}=0.05$ and $\mathrm{RSMR}=0.07$ ). The indirect effect of the depressive symptomatology of MS patients in physical QoL was partially mediated by caregiver burden (mediation effect $=-181,95 \%$ confidence inter$\mathrm{val}=-273$ to $-097, p<.01)$ and by the perceived consequences of the illness (mediation effect $=-134 ;$ 95\% confidence interval $=-243$ to $-0.052, p<.01)$. In turn, the indirect effect of patients' depressive symptomatology, on mental QoL, was partially mediated by the patients' perception of the illness identity (mediation effect $=-079$; 95\% confidence interval $=-153$ to$0.029, p<.01)$ and by caregivers' depressive symptomatology (mediation effect $=-043 ; 95 \%$ confidence interval $=-.105$ to -.007 , $p<.05)$. Also, the indirect effect of age on physical QoL was partially mediated by patients' depressive symptomatology (mediation effect $=-123 ; 95 \%$ confidence interval $=-249$ to $-035, p<.01$ ), as well as the indirect effect on mental QoL, which was fully mediated by patients' depressive symptomatology (mediation effect $=-0.203 ; 95 \%$ confidence interval $=-359$ to $-060, p<.01$ ).

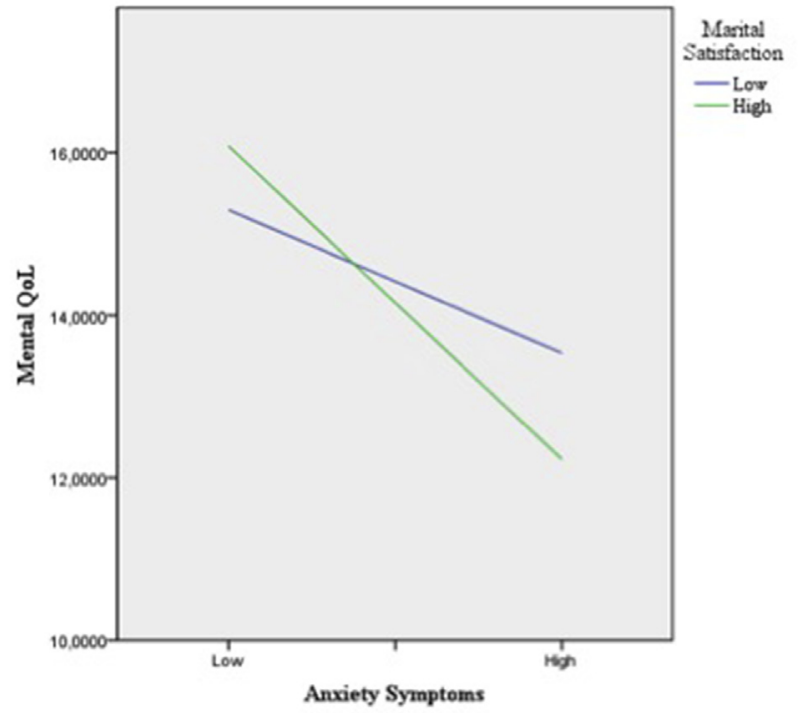

Fig. 1. Marital satisfaction as a moderator between patients' psychological morbidity and QoL.

Finally, there was an indirect effect of level of disability on patient's physical QoL that was partially mediated by caregiver burden (mediation effect $=-185,95 \%$ confidence interval $=-324$ to -0.89 , $p<.01$ ), (Table 2 and Fig. 2).

\section{Discussion}

This study analyzed the relationship between patients and caregivers' variables on patients' QoL. Results showed that lower marital satisfaction, greater perception of illness consequences, more negative emotional representations and illness identity were associated with worse physical and mental QOL. The literature has shown that patients who were less satisfied with the quality of their relationship reported worse QoL. ${ }^{65}$ The study by Aalto et al. ${ }^{40}$ corroborated these results since the perception of illness identity and consequences were related to poorer QoL. In this study, a greater perception of treatment control was associated with better physical QoL. Patients with a more positive perception of MS perceived the disease as less serious and more controllable, leading to less severe consequences, reflecting in better satisfaction with physical QoL. ${ }^{42}$ In turn, patients with depressive symptoms have shown worse physical QoL. Amato, Ponziani, Rossi et al. ${ }^{19}$ argued that depression is one of the most significant predictors of physical QoL, in patients with MS because it influences perception about their health status, which has implications at the physical level. Patients with a greater perception of illness periodicity reported worse mental QoL, probably due to the perception that MS will last a long time leading the patient to feel limited, with repercussion in the QoL. ${ }^{42}$

The results also showed that patients with a poor understanding of the illness (coherence) showed better mental QoL. This result is

Table 1

Results of pearson correlation between patients and caregiver variables with patients' physical and mental QoL.

\begin{tabular}{|c|c|c|c|c|c|c|c|c|c|c|c|c|c|c|c|}
\hline Variables & 1 & 2 & 3 & 4 & 5 & 6 & 7 & 8 & 9 & 10 & 11 & 12 & 13 & 14 & 15 \\
\hline Mental QoL & $-.292^{*}$ & $-.669^{* *}$ & $-.745^{* *}$ & -.058 & $-.488^{* *}$ & .010 & .194 & $-.518^{* *}$ & $-.383^{* *}$ & $-.545^{* *}$ & $-.465^{* *}$ & .019 & -.219 & $-.289^{*}$ & $-.326 * *$ \\
\hline Physical QoL & .002 & -.169 & $-.526^{* *}$ & -.088 & $-.462^{* *}$ & .081 & $.218^{*}$ & -.154 & -.064 & $-.299 * *$ & $-.215^{*}$ & -.091 & $-.266^{*}$ & $-.369^{* *}$ & $-.503^{* *}$ \\
\hline
\end{tabular}

${ }^{* *} p<.01,{ }^{*} p<.05$.

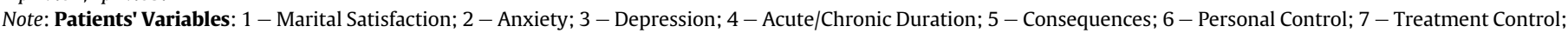

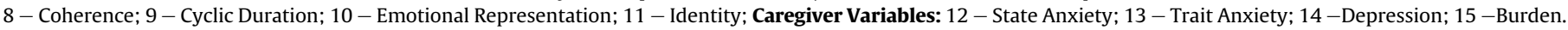


Table 2

Standardized indirect mediation effects.

\begin{tabular}{|c|c|c|c|c|c|c|}
\hline Independent Variable & Mediator Variable & Dependent Variable & B mean indirect effect & SE of mean & $\begin{array}{l}\text { 95\% CI mean } \\
\text { Indirect effect (lower and upper) }\end{array}$ & $p$ value \\
\hline P_Age & P_Depression & P_QoL Mental & -.203 & .079 & $-.359 ;-.035$ & .007 \\
\hline P_Age & P_Depression & P_QoL Physical & -.123 & .053 & $-.249 ;-.035$ & .005 \\
\hline P_Disability & C_Burden & P_QoL Physical & -.185 & .057 & $-.324 ;-.089$ & .001 \\
\hline P_Depression & C_Burden & P_QoL Physical & -.181 & .044 & $-.273 ;-.097$ & .001 \\
\hline P_Depression & C_Depression & P_QoL Mental & -.043 & .024 & $-.105 ;-.007$ & .021 \\
\hline P_Depression & P_Identity & P_QoL Mental & -.079 & .031 & $-.153 ;-.029$ & .001 \\
\hline P_Depression & P_Consequences & P_QoL Physical & -.134 & .048 & $-.243 ;-.052$ & .002 \\
\hline P_Depression & C_Burden & P_QoL Physical & -.210 & .065 & $-.341 ;-.091$ & .001 \\
\hline P_Identity & P_Consequences & P_QoL Physical & -.193 & .059 & $-.310 ;-.084$ & .001 \\
\hline
\end{tabular}

P - Patient Variables; C - Caregiver Variables.

interesting, suggesting the need to assess the information provided to patients concerning MS. However, this result needs to be interpreted with caution since it is based on a single question of the Revised Illness Perception Questionnaire. Future studies should pursue this hypothesis further regarding the pros and cons of information that is transmitted to MS patients.

In caregivers, greater burden was associated with worse physical and mental QoL in patients, probably because more overloaded caregivers express more financial constraints and less involvement in leisure activities, being more predisposed to have psychological morbidity and worse physical health, leading the worst QoL in patients. ${ }^{66}$ These results also are true in caregivers who presented depressive symptoms, since the latter also negatively influence one's caregiving. ${ }^{67}$ Caregivers with depressive symptoms provide less appropriate care to patients. ${ }^{19}$ Higher trait anxiety in the caregiver, was related with lower patient's physical QoL probably because anxiety leads to a less effective caregiving, which may influence the patient's physical QoL and the physical manifestations of the caregiver's anxiety may also induce similar reactions in the patient. ${ }^{28}$ Regarding physical QoL, older patients, with a higher degree of incapacity showed lower physical QoL. Age has been associated with greater disability and physical limitations, and therefore, it makes intuitive sense that older patients with more limitations report lower QoL. ${ }^{14,45}$

Patient's marital satisfaction played a moderating role in the relationship between patients' anxious symptoms and their mental QoL, with the relationship being more intense when marital satisfaction was higher. This result is curious. A study by Ferreira et al. ${ }^{68}$, in patients with chronic low back pain found similar results, with greater functional disability being more intensely associated with worse QoL, in balanced families when compared with less functional families. Therefore, it seems that patients with a satisfactory marital relationship are those who feel the most, the negative impact of anxiety on mental QoL and vice versa.

Caregiver burden partially mediated the relationship between patients' depressive symptomatology and physical QoL. A study by Jeong, Jeong, Kim et al. ${ }^{69}$ has shown that caregiver burden had a mediating effect between the relationship with the patient and QoL, in caregivers. Since the patient's depressive symptomatology is associated with a poorer $\mathrm{QoL},{ }^{19}$ these results allow us to speculate that this relationship may be affected by the caregiver burden. The caregiver may be less available to the patient, with repercussions in the patient's depressive symptomatology and, consequently, worse QoL. The perception of the consequences of MS also played a partial mediating role in this relationship. On the other hand, patients' perception regarding illness identity partially mediated the relationship between patients' depressive symptomatology and Mental QoL. In a study with chronically ill patients, perceptions about the illness have been found to mediate the relationship between the effects of disease severity (which includes an emotional reaction to the illness as morbidity) and QoL. ${ }^{40}$

Caregivers' depressive symptoms also partially mediated this relationship. One may hypothesize that patients with depressive symptomatology may make more emotional demands on the caregiver, reflecting on their depressive symptoms, which may affect the act of caring and have repercussions on a poorer QoL.

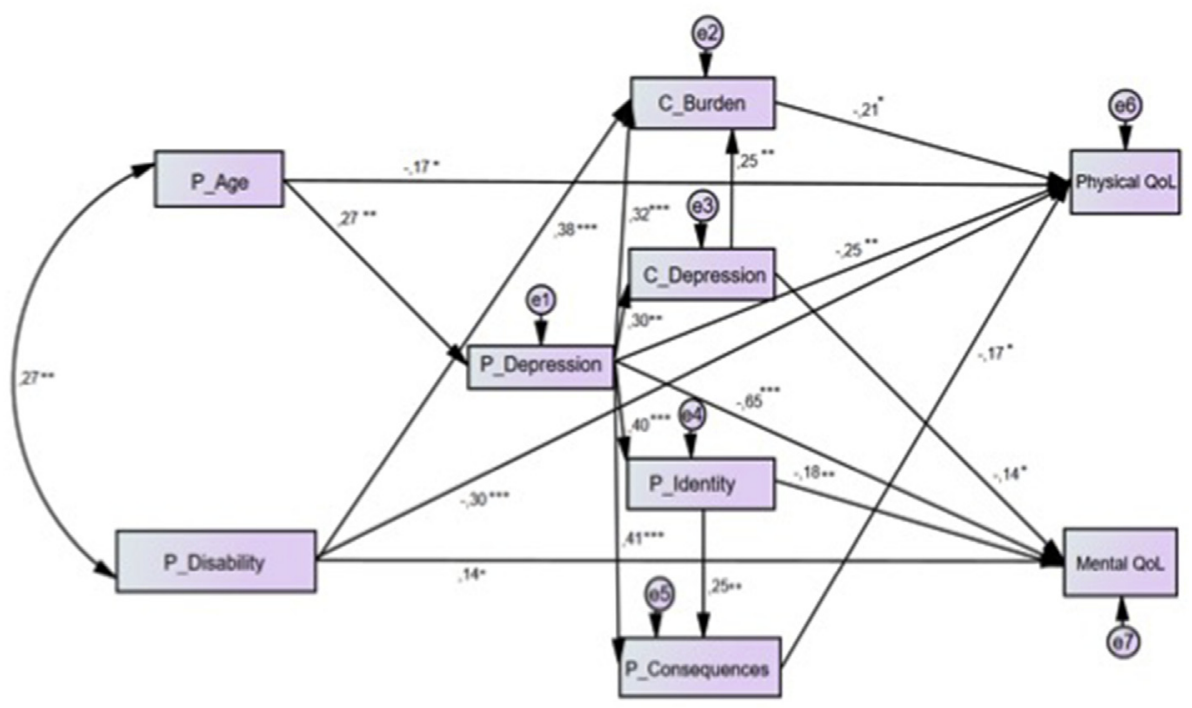

Fig. 2. Final model with variables with letter $P$ referring to the patient and with $C$ to the caregiver. 
Also, patient's depressive symptoms partially mediated the relationship between the patient's age and physical QoL, and fully mediated the relationship between age and mental QoL. Older patients are more likely to present depressive symptomatology and, as already mentioned, depressive symptoms is one of the most significant negative predictors of QoL. ${ }^{19}$ Finally, caregiver burden partially mediated the relationship between patients' disability and physical QoL, which is in accordance with the Ertekin et al. ${ }^{31}$ study, insofar as the greater caregiver burden was reflected in less adjusted care regarding patients' needs, leading to poorer patient Physical QoL. In fact, caregiver's burden assumes a significant influence on patients' QoL, which makes us believe that caregivers who have greater demands in the various domains of their lives, including caring, may end up, in the long term, suffering greater weariness and being less responsive, leading the patients they care for, to feel less illness adaptation that may translate into a poorer QoL for them. Although a transversal design does not allow for causality inferences, the fact that the model tested was theoretically driven, provides meaningful interpretation of the relationships found. Future studies should focus on caregivers' psychological variables, such as burden, and take into account patient's degree of incapacity, in order to analyze their impact on patients and caregivers' QoL in order to inform intervention in a patient-caregiver context.

\section{Limitations}

There are some limitations in this study that need to be acknowledged: the sample size; the cross-sectional design; the use of only self-report measures and the fact that patients were only collected in one major hospital. Future studies should employ a longitudinal design and assess QoL, over time, in both patients and caregivers.

\section{Conclusion}

Taking into account the results, intervention should focus on patients and caregivers in a dyadic context, particularly when caregivers are spouses, since marital satisfaction was a moderating variable in the relationship between patients' anxiety and Mental QoL. Therefore, marital satisfaction may be a protective factor in MS and future studies should replicate this resut in other samples. Intervention should also focus on depressive symptomatology and illness representations in patients (e.g. identity and consequences of illness), since they played a mediating role in the relationship between depressive symptoms and QoL. Regarding caregivers, intervention should focus on burden and depressive symptoms contributing indirectly to patients' QoL, as well.

The results also highlight the need for multidisciplinary teams in MS to include a clinical and health psychologist to address patients and caregivers' psychological needs in order to promote the Qol of both.

\section{Conflicts of interest}

The authors report no conflict of interest.

\section{Funding}

This work received no funding.

\section{Appendix A. Supplementary data}

Supplementary data to this article can be found online at https://doi.org/10.1016/j.dhjo.2019.03.007.

\section{References}

1. Boiko A, Vorobeychik G, Paty D, Devonshire V, Sadovnick D. Early onset multiple sclerosis: a longitudinal study. Neurology. 2002:59(7):1006-1010.

2. DeLuca J, Genova HM, Hillary FG, Wylie G. Neural correlates of cognitive fatigue in multiple sclerosis using functional MRI. J Neurol Sci. 2008;270(1):28-39. https://doi.org/10.1016/j.jns.2008.01.018.

3. World Health Organization [WHO]. Atlas. Multiple Sclerosis Resources in the World, 2008. World Health Organization; 2008.

4. Abreu P, Mendonça MT, Guimarães J, Sá MJ. Esclerose múltipla: epidemiologia, fisiopatologia e diagnóstico diferencial. Sinapse. 2012:12(2):5-14.

5. Hatch MN, Schaumburg CS, Lane TE, Keirstead HS. Endogenous remyelination is induced by transplant rejection in a viral model of multiple sclerosis. J Neuroimmunol. 2009;212(1):74-81. https://doi.org/10.1016/j.jneuroim.2009. 05.002 .

6. Lampert PW. Autoimmune and virus-induced demyelinating diseases. A review. Am J Pathol. 1978;91(1):176.

7. De Sá J. Epidemiology of multiple sclerosis in Portugal and Spain. Rev Neurol. 2010;51(7):387.

8. Multiple Sclerosis International Federation [MSIF]. Atlas da EM 2013: Mapeamento da Esclerose Múltipla no Mundo; 2013. Retrived from: http://www.msif. org/aboutus/advocacy/atlas/atlas-of-ms/.

9. Khan F, Turner-Stokes L, Ng L, Kilpatrick T. Multidisciplinary rehabilitation for adults with multiple sclerosis. Postgrad Med. 2008;84(993):385. https://doi.org/ 10.1136/jnnp.2007.127563.

10. Andrés C, Guillem A. Una aproximación sobre la calidad de vida en pacientes com esclerosis múltiple. Rev Neurol. 2000;30:1229-1234.

11. Lublin FD, Reingold SC. Defining the clinical course of multiple sclerosis results of an international survey. Neurology. 1996:46(4):907-911.

12. Gadoth N. Multiple sclerosis in children. Brain Dev. 2003;25(4):229-232. https://doi.org/10.1016/S0387-7604(03)00035-4.

13. Quintanilha RS, de Lima LR. Avaliação da qualidade de vida em portadores de esclerose múltipla. J Nurs UFPE/Rev Enferm UFPE. 2010;4(1).

14. Janssens AC, Van Doorn PA, De Boer JB, et al. Anxiety and depression influence the relation between disability status and quality of life in multiple sclerosis. Mult Scler J. 2003;9(4):397-403. https://doi.org/10.1191/1352458503ms930oa.

15. Feinstein A, Magalhaes S, Richard JF, Audet B, Moore C. The link between multiple sclerosis and depression. Nat Rev Neurol. 2014;10(9):507-517. https://doi.org/10.1038/nrneurol.2014.139.

16. Minden SL, Feinstein A, Kalb RC, et al. Evidence-based guideline: assessment and management of psychiatric disorders in individuals with MS report of the guideline development subcommittee of the american academy of neurology. Neurology. 2014;82(2):174-181. https://doi.org/10.1212/WNL.000000000 0000013.

17. Marrie RA, Reingold S, Cohen J, et al. The incidence and prevalence of psychiatric disorders in multiple sclerosis: a systematic review. Mult Scler J. 2015;21(3):305-317. https://doi.org/10.1177/1352458514564487.

18. Boeschoten RE, Braamse AM, Beekman AT, et al. Prevalence of depression and anxiety in multiple sclerosis: a systematic review and meta-analysis. J Neurol Sci. 2016;372(7):331-341. https://doi.org/10.1016/j.jns.2016.11.067.

19. Amato MP, Ponziani G, Rossi F, Liedl CL, Stefanile C, Rossi L. Quality of life in multiple sclerosis: the impact of depression, fatigue and disability. Mult Scler J. 2001:7(5):340-344.

20. Dahl OP, Stordal E, Lydersen S, Midgard R. Anxiety and depression in multiple sclerosis. A comparative population-based study in Nord-Trøndelag County, Norway. Mult Scler J. 2009;15(12):1495-1501. https://doi.org/10.1177/ 1352458509351542.

21. Shabani A, Moghadam JA, Panaghi L, Seddigh A. Anxiety disorders in multiple sclerosis: significance of obsessive-compulsive disorder comorbidity. J Res Med Sci. 2007:12(4):172-177.

22. Da Silva A, Vilhena E, Lopes A, Santos E, Gonçalves M, Pinto C, et al. Depression and anxiety in a Portuguese MS population: Associations with physical disability and severity of disease. J Neurol Sci. 2011;306(1-2):66-70. https:// doi.org/10.1016/j.jns.2011.03.042.

23. Tan-Kristanto S, Kiropoulos LA. Resilience, self-efficacy, coping styles and depressive and anxiety symptoms in those newly diagnosed with multiple sclerosis. Psychol Health Med. 2015;20(6):635-645. https://doi.org/10.1080/ 13548506.2014.999810.

24. Kikuchi H, Mifune N, Niino M, et al. Structural equation modeling of factors contributing to quality of life in Japanese patients with multiple sclerosis. BMC Neurol. 2013:13(1):10.

25. Niino M, Kikuchi H, Mifune N, Kikuchi S. Structural equation modeling for interventions to improve quality of life in patients with multiple sclerosis. Neurology. 2012:78(1):7-95.

26. Liu XJ, Ye HX, Li WP, Dai R, Chen D, Jin M. Relationship between psychosocial factors and onset of multiple sclerosis. Eur Neurol. 2009;62(3):130-136. https://doi.org/10.1159/000226428.

27. Costa-Requena G, Cristófol R, Cañete J. Caregivers morbidity in palliative care unit: predicting by gender, age, burden and self-esteem. Support Care Canc. 2012;20(7):1465-1470. https://doi.org/10.1007/s00520-011-1233-6.

28. Argyriou AA, Karanasios P, Ifanti AA, et al. Quality of life and emotional burden of primary caregivers: a case-control study of multiple sclerosis patients in Greece. Qual Life Res. 2011;20(10):1663-1668. https://doi.org/10.1007/ s11136-011-9899-2. 
29. Patti F, Amato MP, Battaglia MA, et al. Caregiver quality of life in multiple sclerosis: a multicentre Italian study. Mult Scler. 2007. https://doi.org/10.1177/ 1352458506070707.

30. Dunn J. Impact of mobility impairment on the burden of caregiving in individuals with multiple sclerosis. Expert Rev Pharmacoecon Outcomes Res. 2010;10(4):433-440. https://doi.org/10.1586/ERP.10.34.

31. Ertekin Ö, Özakbaş S, İdiman E. Caregiver burden, quality of life and walking ability in different disability levels of multiple sclerosis. NeuroRehabilitation. 2014;34(2):313-321. https://doi.org/10.3233/NRE-131037.

32. Donzé C, Lenne B, Jean Deleglise AS, Kempf C, Bellili Y, Hautecoeur P. EVASEP: a noninterventional study describing the perception of neurologists, patients, and caregivers on caregivers' role in the support of patients suffering from multiple sclerosis treated with subcutaneous interferon beta 1a. Mult Scler Int. 2016. https://doi.org/10.1155/2016/4986073, 2016.

33. Pakenham KI, Finlayson M. Caregiving. In: Finlayson M, ed. Multiple Sclerosis Rehabilitation: From Impairment to Participation. Boca Raton: CRC Press; 2012: 497-526.

34. Hammerschmidt H, Norgren MBP, Sharlin SA, Souza RM, Kaslow F. Satisfação conjugal em casamentos de longa duração: Uma construção possível. Estud Psicolog. 2004;9(3):575-584.

35. Gordon PA, Perrone KM. When spouses become caregivers: counseling implications for younger couples. J Rehabil. 2004;70(2):27.

36. Pruchno R, Wilson-Genderson M, Cartwright FP. Depressive symptoms and marital satisfaction in the context of chronic disease: a longitudinal dyadic analysis. J Fam Psychol. 2009;23(4):573-584. https://doi.org/10.1037/ a0015878.

37. Kaptein AA, Helder DI, Scharloo M, et al. Illness perceptions and coping explain well-being in patients with Huntington's disease. Psychol Health. 2006;21(4): 431-446. https://doi.org/10.1080/14768320500456947.

38. Jopson NM, Moss-Morris R. The role of illness severity and illness representations in adjusting to multiple sclerosis. J Psychosom Res. 2003;54(6):503-511. https://doi.org/10.1016/S0022-3999(02)00455-5.

39. French DP, Cooper A, Weinman J. Illness perceptions predict attendance at cardiac rehabilitation following acute myocardial infarction: a systematic review with meta-analysis. J Psychosom Res. 2006;61(6):757-767. https:// doi.org/10.1016/j.jpsychores.2006.07.029.

40. Aalto AM, Aro AR, Weinman J, Heijmans M, Manderbacka K, Elovainio $M$. Sociodemographic, disease status, and illness perceptions predictors of global self-ratings of health and quality of life among those with coronary heart disease - one year follow-up study. Qual Life Res. 2006;15(8):1307-1322. https://doi.org/10.1007/s11136-006-0010-3.

41. Moss-Morris R, Weinman J, Petrie K, Horne R, Cameron L, Buick D. The revised illness perception questionnaire (IPQ-R). Psychol Health. 2002;17(1):1-16. https://doi.org/10.1080/08870440290001494.

42. Petrie KJ, Jago LA, Devcich DA. The role of illness perceptions in patients with medical conditions. Curr Opin Psychiatr. 2007;20(2):163-167.

43. Lobentanz IS, Asenbaum S, Vass $\mathrm{K}$, et al. Factors influencing quality of life in multiple sclerosis patients: disability, depressive mood, fatigue and sleep quality. Acta Neurol Scand. 2004;110(1):6-13. https://doi.org/10.1111/j.16000404.2004.00257.x.

44. Theofilou P. Sociodemographic and clinical determinants of quality of life and health representations in Greek patients with multiple sclerosis. Eur J Psychol. 2013;9(1):33. https://doi.org/10.5964/ejop.v9i1.387.

45. Baumstarck-Barrau K, Simeoni MC, Reuter F, et al. Cognitive function and quality of life in multiple sclerosis patients: a cross-sectional study. BMC Neurol. 2011;11(1):17. https://doi.org/10.1186/1471-2377-11-17.

46. Livneh H. Psychosocial adaptation to chronic illness and disability a conceptual framework. Rehabil Counsel Bull. 2001;44(3):151-160.

47. Kurtzke JF. Rating neurologic impairment in multiple sclerosis: an expanded disability status scale (EDSS). Neurology. 1983;33(11):1444.

48. Vickrey BJ, Hays RD, Harooni R, Myers LW, Ellison GW. A health-related quality of life measure for multiple sclerosis. Qual Life Res. 1995;4:187-206. https:// doi.org/10.1007/BF02260859.

49. Pedro L, Pais-Ribeiro JL. Características psicométricas dos instrumentos usados para avaliar a qualidade de vida na esclerose múltipla: uma revisão bibliográfica. Fisioter Pesqui. 2008:309-314. https://doi.org/10.1590/S180929502008000300016.

50. Figueiras MJ, Machado VA, Alves NC. Os modelos de senso-comum das cefaleias crónicas nos casais: relação com o ajustamento marital. Análise Psicol. 2002;20(1):77-90.

51. Zigmond AS, Snaith RP. The hospital and anxiety and depression scale. Acto Psiquiatr Scand. 1983;7:361-370.

52. Pais-Ribeiro J, Silva I, Ferreira T, Martins A, Meneses R, Baltar M. Validation study of a Portuguese version of the hospital anxiety and depression scale. Psychol Health Med. 2007;12(2):225-237. https://doi.org/10.1080/ 13548500500524088.

53. Sousa C, Pereira MG Morbilidade psicológica e representações da doença em pacientes com esclerose múltipla: Estudo de validação da "Hospital, Anxiety and Depression Scale" (HADS). [Psychological Morbidity and Illness representations in patients with multiple sclerosis: Validation study of HADS]. 2008.

54. Hudson WW. The WALMYR Assessment Scales Scoring Manual. Tempe, AZ: WALMYR Publishing Co; 1992.

55. Pereira G, Ramalho V, Dias P. Psychological variables in pregnancy: does age matter? An exploratory study Rev Port Psicossomática. 2002:4(1):131-140.

56. Given CW, Given B, Stommel M, Collins C, King S, Franklin S. The caregiver reaction assessment (CRA) for caregivers to persons with chronic physical and mental impairments. Res Nurs Health. 1992;15(4):271-283.

57. Pereira MG, Soares AJ. Sobrecarga em cuidadores informais de dependentes de substâncias: adaptação do Caregiver Reaction Assessment (CRA). Psicolog Saúde Doenças. 2011;12(2):304-328.

58. Spielberger CD, Gorsuch RL, Lushene RE, Vagg PR, Jacobs GA. STAI Manual for the State-Trait Anxiety Inventory. Palo Alto. 1970.

59. Silva DR. O inventário de estado-traço de ansiedade (STAI). Avaliação Psicol: Instrumentos validados para a população portuguesa. 2003;1:45-63.

60. Beck AT, Ward $\mathrm{CH}$, Mendelson M, Mock J, Ergbaugh J. An inventory for measuring depression. Arch Gen Psychiatr. 1961;4(6):561-571.

61. McIntyre T, Araújo-Soares V. Inventário da depressão de Beck: estudo de validade numa amostra de doentes com dor crónica. In: Actas de comunicacõos científicas. VI Conferência Internacional de Avaliação Psicológica: Formas e Contextos. 1999:245-255.

62. Bentler PM, Chou C-P. Practical issues in structural equation modeling. Socio Methods Res, 1987:16:78-117.

63. Hair Jr JF, Celsi MW, Ortinau DJ, Bush RP. Essentials of Marketing Research. 3 th Ed. New York: McGraw-Hill; 2013.

64. Hayes AF. Introduction to Mediation, Moderation, and Conditional Process Analysis. New York: The Guilford Press; 2013.

65. Williams RM, Turner AP, Hatzakis M, et al. Social support among veterans with multiple sclerosis. Rehabil Psychol. 2004;49(2):106. https://doi.org/10.1037| 0090-5550.49.2.106.

66. Miyashita M, Narita Y, Sakamoto A, et al. Care burden and depression in caregivers caring for patients with intractable neurological diseases at home in Japan. J Neurol Sci. 2009;276(1):148-152. https://doi.org/10.1016 j.jns.2008.09.022.

67. Knight RG, Devereux RC, Godfrey HP. Psychosocial consequences of caring for a spouse with multiple sclerosis. J Clin Exp Neuropsychol. 1997;19(1):7-19. https://doi.org/10.1080/01688639708403832.

68. Ferreira MSM, Pereira MDG. O papel moderador do tipo de família na relação entre incapacidade funcional e qualidade de vida em doentes com lombalgia crônica. Ciência Saúde Coletiva. 2016;21(1):303-309. https://doi.org/10.1590/ 1413-81232015211.01012015.

69. Jeong YG, Jeong YJ, Kim WC, Kim JS. The mediating effect of caregiver burden on the caregivers' quality of life. J Phys Ther Sci. 2015;27(5):1543-1547. 